formed. It must be conceded that the information provided will be of great use to research workers in the field, and the publishers' claim that the book serves as a reference and guide to the literature is well justified. This function is, however, vulnerable in view of the rapid development of the subject since 1968 and in many respects the book is already outdated. Thus one questions the whole concept of producing a review of this type in book form rather than as a regularly updated series in the review literature. A glance at the price strongly reinforces this view.

A. BEWICK

\section{Elements in Meteorites}

Handbook of Elemental Abundances in Meteorites. Edited by Brian Mason. (Series on Extraterrestrial Chemistry.) Pp. ix +555. (Gordon and Breach: New York and London, December 1971.) $£ 14.60$ cloth; $£ 5.80$ paper.

The little sample of extraterrestrial material furnished by the meteorites provides the basis for many of our ideas about the early state of the solar system, the origin of the planets and the nature of the Earth's interior. It deserves careful study; and since 1953, and especially in the past decade, an immense amount of detailed chemical analysis, by ever more refined methods, has been carried out on meteorites. This book, sponsored by the International Association of Geochemistry and Cosmochemistry, is an attempt to make the results more accessible.

The result is really a synopsis rather than a handbook. It does not set out to compile the basic data on the chemical constituents of individual meteorites, but furnishes instead a statistical summary of the abundances of the elements in meteorites grouped into classes. Although there are many abundance values appertaining to named meteorites in the book (thirtynine of the sixty-five chapters on individual elements give some such data), this is not the main aim.

It is arguable that, in the present state of knowledge, a true handbook of critically evaluated data would have been more useful than a synopsis. Since the synoptic form was chosen, however, clearly it was desirable to decide firmly on a single classificatory scheme and a uniform set of symbols to be used throughout. This has not been done with a sufficiently firm hand, and the resulting anarchy over terms and notation mars the book. It would have been valuable, too, to have added an agreed classificatory symbol to each of the meteorites in the index of meteorites at the end. It is interesting that most of the twenty-one con- tributors are attracted to the Van Schmus-Wood classification of chondrites, but the editor conspicuously is not.

We begin with a nineteen-page introduction mainly devoted to classification. Unfortunately this does not cover some of the terms and symbols used later in the book. Then follows a chapter on each chemical element arranged in periodic order (the inert gases and rare earths being treated as groups, and $\mathrm{Zr}$ and $\mathrm{Hf}$ together). In each four to twelve-page chapter (but "Inert Gases" gets 38 pages, K 21 pages and $U 20$ pages) there is usually a table giving the range and mean amount of the element, and the number of determinations, in each class of meteorites. Often there will be a diagram giving the distribution of determined values by classes. If you are lucky there will be some values for named meteorites and data on separated minerals. The text consists of notes on the tables, commentary on the reliability of the analytical determinations (very professional) and some remarks on the fractionation of the element with respect to others. References, gathered at the end of each chapter, bring one well up to date, being mostly to work published in the 'sixties.

As a source-book the sphere of usefulness of this volume is difficult to assess. It will be valuable in the teaching of general geochemistry and cosmochemistry, but for this purpose it might well have been briefer. For the research worker analysing meteorites and the theoretician thinking about them, its value may depend on which element is of immediate interest. For some he may find tabulated most or all of what is known: for others he will wish to know more about individual meteorites, and will have to turn back to the original literature (to which the Handbook is an excellent guide).

\section{H. BATTEY}

\section{Glass Structure}

Structure and Crystallization of Glasses. By Werner Vogel. Pp. 246. (Pergamon: Oxford and New York, October 1971.) $£ 7$.

THIS volume is a translation of the original German edition published in 1965. It is an account of the experimental work on liquid-liquid separation and nucleation and crystal growth in glasses carried out by the author and his colleagues in the laboratories of VEB Jena Glass Works of Schott and Gen. The book, which is beautifully produced in large format 8 by 11.5 inches, contains a large number of reproductions of optical and electron micrographs. The publishers can hardly have expected the book to be treated as a textbook but its appearance in English translation will be welcomed in any laboratory where the topics discussed in the book are being investigated or where a project in this field is being considered. It is, however, a difficult book to review, for although it contains clear accounts of some excellent experimental work it could be criticized because it lacks quantitative data. There is, for example, no mention of the measurement of immiscibility temperatures and the heat treatments reported do not reveal any systematic selection.

The book has now been in print for more than six years, however, and its value lies in the record it provides of some excellent pioneering work. This value is enhanced by the detailed descriptions given of the preparation of glasses and the procedures for electron microscopy.

The first sixty pages describe the preparation and study of beryllium fluoride glasses which Vogel regards as "prototypes" of silicate glasses. This is probably the most complete account available of the study of these glasses. $\mathrm{BeF}_{2}$ has the structure of $\beta$-cristobalite and $\mathrm{BeF}_{2}$ glass has the same tetrahedraltype structure as $\mathrm{SiO}_{2}$ with the $\mathrm{Be}-\mathrm{F}$ distance $1.6 \AA$ compared with $1.62 \AA$ for $\mathrm{Si}-\mathrm{O}$. Vogel looks on $\mathrm{BeF}_{2}$ and alkali beryllium fluoride glass systems as "weakened" counterparts of the corresponding silicate systems; certainly the photographs reveal remarkable similarities in the appearance of liquidliquid separation and precipitation of crystals.

Other sections of the book describe studies of $\mathrm{Li}_{2} \mathrm{O}-\mathrm{SiO}_{2}, \mathrm{Na}_{2} \mathrm{O}-\mathrm{B}_{2} \mathrm{O}_{3}-\mathrm{SiO}_{2}$ glass-forming systems as well as commercial compositions used for the preparation of glass-ceramic materials.

Vogel concludes, "The results described . . . confirm that the processes of segregation play a primary part in the conversion of a Pyroceram glass into a ceramic product". By segregation here he means liquid-liquid immiscibility.

In one or two places the translation could be improved but no difficulty arises and the volume will be read with interest by all concerned with these topics.

\section{R. W. Douglas}

\section{Light on Molecules}

The Theory of Optical Activity. By Dennis J. Caldwell and Henry Erying. Pp. viii + 244. (Wiley Interscience: New York and London, November 1971.) £7. THE physical basis of optical activity is very simple to understand and to formulate quantum mechanically, but the application of the theory to the calcula- 